\title{
The Effectiveness of Smoking Cessation Interventions Tailored to Smoking Parents of Children Aged 0-18 Years: A Meta-Analysis
}

\author{
Tessa Scheffers-van Schayck ${ }^{a, b} \quad$ Ajla Mujcic ${ }^{c, d}$ Roy Otten ${ }^{\mathrm{e}-\mathrm{g}}$ Rutger Engels $^{\mathrm{h}}$ \\ Marloes Kleinjan ${ }^{b, i}$ \\ ${ }^{a}$ Epidemiology and Research Support, Trimbos Institute - Netherlands Institute of Mental Health and Addiction, \\ Utrecht, The Netherlands; ${ }^{b}$ Department of Interdisciplinary Social Sciences, Utrecht University, \\ Utrecht, The Netherlands; ${ }^{\mathrm{C}}$ Drugs Monitoring and Policy, Trimbos Institute - Netherlands Institute of \\ Mental Health and Addiction, Utrecht, The Netherlands; ${ }^{\mathrm{d}}$ Erasmus School of Social and Behavioural Sciences, \\ Erasmus University Rotterdam, Rotterdam, The Netherlands; ${ }^{~}$ Research and Development, Pluryn, \\ Nijmegen, The Netherlands; ' Department of Psychology, ASU REACH Institute, Arizona State University, \\ Tempe, AZ, USA; ${ }^{9}$ Developmental Psychopathology, Radboud University, Nijmegen, The Netherlands; \\ hExecutive Board, Erasmus University, Rotterdam, The Netherlands; 'Y Youth, Trimbos Institute - Netherlands \\ Institute of Mental Health and Addiction, Utrecht, The Netherlands
}

\section{Keywords}

Smoking cessation - Parents · Second-hand smoking •

Systematic review $\cdot$ Meta-analysis

\begin{abstract}
Introduction: A meta-analysis was conducted to examine the effectiveness of smoking cessation interventions tailored to parents of children aged 0-18 years. Methods: A systematic search was carried out in Psyclnfo, Embase, and PubMed in March 2020. A manual search of the reference lists of the included studies and systematic reviews related to the topic was also performed. Two authors independently screened the studies based on the following inclusion criteria: (1) effect studies with control groups that examine smoking cessation interventions tailored to parents of children (0-18 years), and (2) full-text original articles written in English and published between January 1990 and February 2020. In total, 18 studies were included in the analyses. The TiDieR checklist and the Cochrane Risk of Bias Tool 2.0 were used to extract data and to assess the risk of bias. Consensus
\end{abstract}

karger@karger.com www.karger.com/ear

Karger"

GOPEN ACCESS
(C) 2020 The Author(s)

Published by S. Karger AG, Basel

This is an Open Access article licensed under the Creative Commons Attribution-NonCommercial-4.0 International License (CC BY-NC) (http://www.karger.com/Services/OpenAccessLicense), applicable to the online version of the article only. Usage and distribution for commercial purposes requires written permission. among authors was reached at each stage. Results: Random-effects meta-analyses were performed. With a total number of 8,560 parents, the pooled relative risk was 1.62 (95\% Cl 1.38-1.90; $p<0.00001)$, showing a modest effect of the interventions on smoking cessation. Overall, $13.1 \%$ of the parents in the intervention conditions reported abstinence versus $8.4 \%$ of the parents in the control conditions. Discussion/Conclusion: Smoking cessation interventions tailored to parents are modestly effective. To increase the effectiveness and the impact of these interventions in terms of controlling tobacco use and public health, it is crucial for further research to explore how these interventions can be improved.

(c) 2020 The Author(s)

Published by S. Karger AG, Basel

\section{Introduction}

Children's exposure to secondhand smoke (SHS) is a worldwide problem. Approximately half a billion children are exposed to SHS at home [1]. Parental smoking 
in the home is a major source of children's exposure to SHS and thirdhand smoke (THS) [2,3]. Ample evidence has illustrated that exposure to SHS leads to serious health consequences for infants, children, and adolescents [46]. For example, children's exposure to SHS has been associated with sudden infant death syndrome, reduced lung function, and lower respiratory illnesses $[4,6]$. In addition to SHS, children can also be exposed to THS. THS "consists of residual tobacco smoke pollutants that remain on surfaces and in dust after tobacco has been smoked, are re-emitted into the gas phase, or react with oxidants and other compounds in the environment to yield secondary pollutants" [3]. The presence of THS in the air, in dust, and on surfaces indicates that very young children are particularly vulnerable to THS due to crawling, hand-to-mouth and object-to-mouth behaviors, and playing near the floor [7]. To date, limited research has been published to identify the health consequences of exposure to THS in children $[7,8]$. However, it is known that THS leads to exposure to toxic tobacco smoke pollutants $[7,8]$. In addition to the health consequences of children's exposure to parental smoking, children of smoking parents are more likely to smoke in the future $[9,10]$. This emphasizes the need to protect children from exposure to parental smoking.

Multiple interventions that primarily focus on reducing children's exposure to SHS in the home have been developed, examined, and shown to be effective (e.g., Harutyunyan et al. [11] and Hovell et al. [12]). However, the gains of interventions aimed at reduction to SHS exposure may be limited compared to interventions that aim at parental smoking cessation. First, since the focus of these interventions is reduction of children's exposure to SHS and not parental smoking cessation per se, these interventions are not likely to eliminate the detrimental health consequences of smoking to parents themselves. In addition, SHS reduction interventions are also not likely to completely eliminate children's exposure to THS. However, when parents quit smoking, children's exposure to SHS and THS is eliminated [2], the risk for children to start smoking diminishes [13], and the odds of morbidity and mortality for parents themselves decrease [14]. Third, interventions that primarily focus on parental smoking cessation, instead of on reduction of children's exposure to SHS and parental smoking cessation, have also been shown to be relatively more effective [15]. Fourth, research has shown that many parents want to quit smoking and even try to quit smoking [16]. In brief, based on this evidence, it is essential to examine interventions that exclusively aim at parental smoking cessation and not at reducing children's exposure to SHS. Parental smoking cessation may not be different from adult smoking cessation per se. However, the motivation to quit smoking could be different among parents than among other adult smokers (e.g., parents want to quit smoking because of their children's health $[17,18]$ ).

To date, multiple interventions that mainly aim at parental smoking cessation have been examined. Several (systematic) reviews and meta-analyses have assessed parental smoking cessation rates of SHS reduction and cessation interventions [15, 19-21]. To our knowledge, only one meta-analysis (performed in 2012) examined interventions in which parental smoking cessation was the main objective [15]. However, this analysis was carried out as a subgroup analysis and included only five studies. Since 2012, several new studies (e.g., see Schuck et al. [22], Borrelli et al. [23], and Scheffers-van Schayck et al. [24]) have been published, which requires an update. In addition, this previous meta-analysis focused on interventions tailored to parents of young children (aged between 0 and 6 years), thereby limiting the contribution as the effects of parental smoking are not limited to early childhood and the level of children's exposure to parental smoking increases when children become older $[25,26]$. To summarize, there is a gap in evidence on the effectiveness of interventions that mainly aim at parental smoking cessation. Because of this gap and the potential of these interventions to eliminate the detrimental health consequences of smoking and exposure to smoking, the aim of this meta-analysis was to examine effect studies testing interventions (e.g., telephone counseling) that mainly aim at helping parents (of children and adolescents aged $0-18$ years) to quit smoking.

\section{Methods}

Search Strategy and Data Selection Process

This study was conducted in accordance with the PRISMA statement [27] and registered in the Prospero database of systematic reviews (registration No. CRD42018086797). In collaboration with the first author, a professional information expert in searches for systematic reviews performed a systematic literature search in PsycInfo, Embase, and PubMed in March 2020. The search terms that were used included a combination of terms for parents, cessation, program, and smoking. In addition, a manual search of the reference lists of the included studies, systematic reviews, and meta-analyses related to our topic was performed. To be included, the studies had to be: (1) effect studies (e.g., randomized controlled trials; RCTs) with control groups that examined smoking cessation interventions tailored to current parents (of children and adolescents $0-18$ years old); (2) studies of which the primary outcome was smoking cessation (e.g., self-reported 7-day point prevalence abstinence; PPA) and not reduction in children's exposure to SHS 


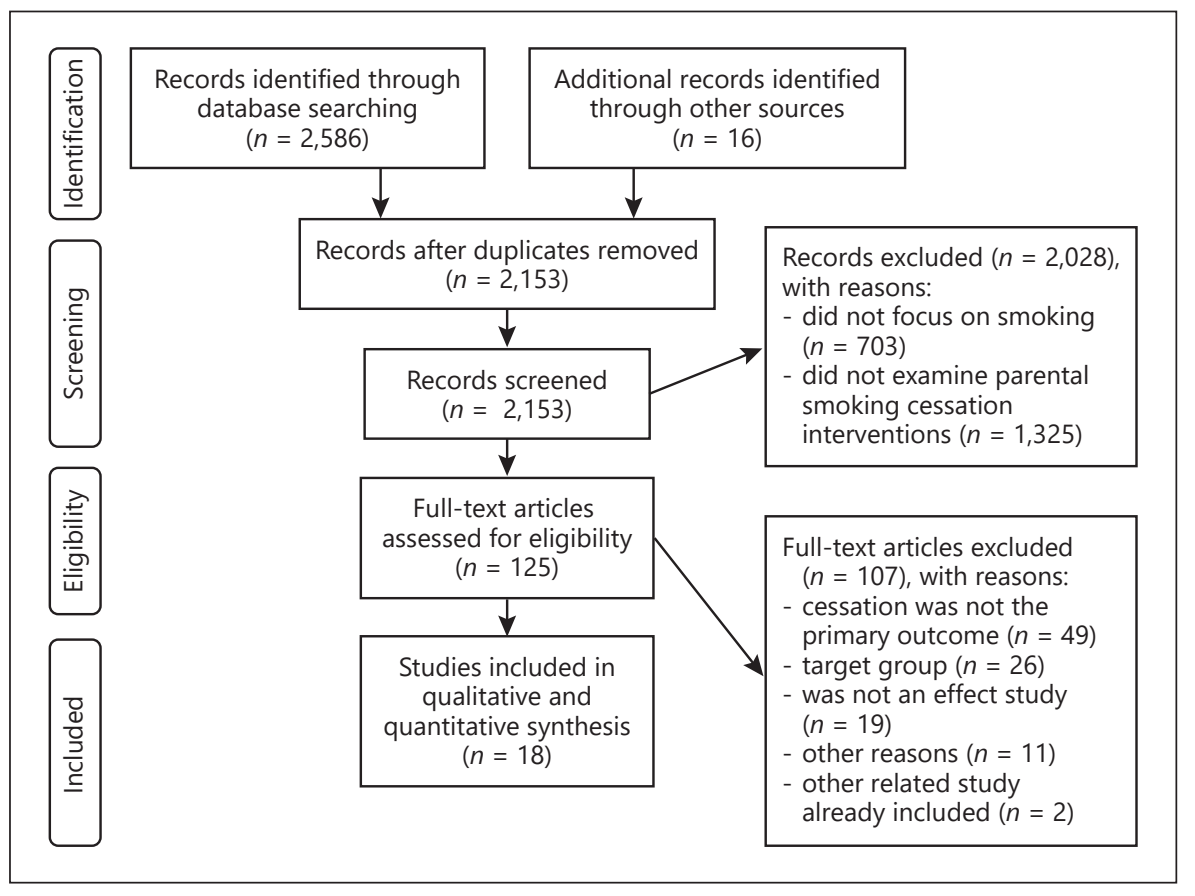

Fig. 1. PRISMA study flow diagram.

or relapse prevention, and (3) full-text original articles written in English and published between January 1990 and February 2020. Studies that involved cessation interventions for pregnant women were excluded because pregnant women who smoke are a specific target group and more likely to have multiple and complex problems in addition to their nicotine addiction (e.g., family and financial problems) [28]. Studies that aimed at both smoking cessation and relapse prevention/reduction in SHS exposure were only included if smoking cessation was the primary outcome. In cases where full-text articles were not available, attempts were made to obtain the full-text articles from the authors.

Figure 1 presents the PRISMA study flow diagram [27]. After excluding duplicates, the titles and abstracts of 2,153 studies were independently screened by 2 authors (T.S.-v.S. and A.M.) based on the inclusion criteria (agreement: 95.8\%; Cohen's kappa $=0.55$ ). If there were any doubts about the eligibility of studies, studies were included for full-text screening. At this stage, 2,028 studies were excluded. The full text of the remaining 125 potential eligible studies were independently read by the same 2 authors and checked for inclusion (agreement: 89.6\%; Cohen's kappa = 0.72). Of these 125 studies, 107 were excluded due to various reasons (see Fig. 1). Overall, 18 studies were included in the subsequent analyses. Any disagreements between the two screening authors throughout the data selection process were resolved by discussion and, if necessary, by consulting a third author (R.O. or M.K.).

Data Extraction Process and Risk of Bias Assessment

One author (T.S.-v.S.) used the TiDieR checklist [29] to extract data from the 18 included articles. For four studies [30-33], four other articles were also used for the data extraction [34-37]. A second author (A.M.) and a research assistant checked whether the data extraction was done correctly (each checked approximately half of the articles). The following data were extracted concerning the study characteristics: authors, year of publication, methodological and sample characteristics (e.g., study design, country, age of parents, sample size), and primary outcomes and measurements (e.g., measurement method and biochemical validation; see Table 1). In addition, a variety of intervention characteristics were extracted (e.g., theories or theoretical principles, providers, activities, and materials; see Table 2). The following data were extracted for the overall statistical analysis: number of parents in the intervention and control conditions, and number of parents that reported abstinence in the intervention and control conditions. In addition, for the four subgroup analyses the following data were extracted: (1) theoretical basis of the intervention (yes/no); (2) provision of nicotine replacement therapy (NRT) during the intervention (yes/ no); (3) risk of bias judgement (low risk of bias/some concerns about bias/high risk of bias), and (4) intervention that parents in the control condition received (passive/active). Interventions that were provided to the control condition (e.g., a self-help brochure) were categorized as "active" if the interventions focused on smoking cessation. In contrast, if the interventions did not focus on smoking cessation, they were categorized as "passive."

The risk of bias was assessed using the Cochrane Risk of Bias Tool 2.0 [38]. Two authors (T.S.-v.S. and A.M.) independently assessed the risk of bias at outcome level for the 17 studies on three levels (i.e., low risk of bias, some concerns about bias, and high risk of bias). Because the authors of one of the included studies [24] were for the greater part also involved in the present meta-analysis, the risk of bias assessment was conducted by 2 independent researchers. More specifically, the 18 studies were assessed on the following criteria: (1) randomization process (i.e., randomization and concealment); (2) blinding of participants, caretakers, and research staff; (3) missing outcome data; (4) measurement of the outcome, and (5) selection of the reported results. Disagreements between the authors in the process of data extraction and risk of 


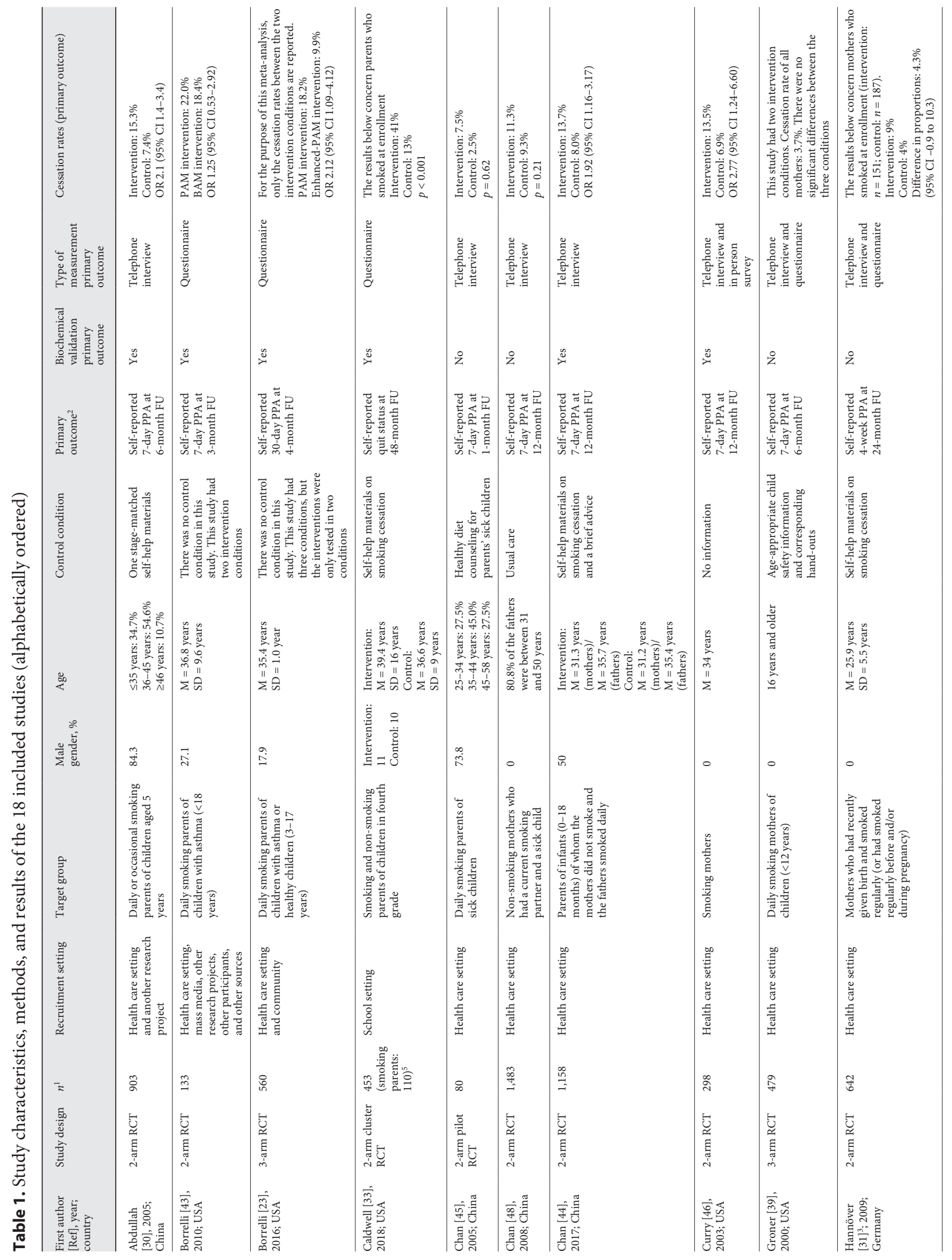




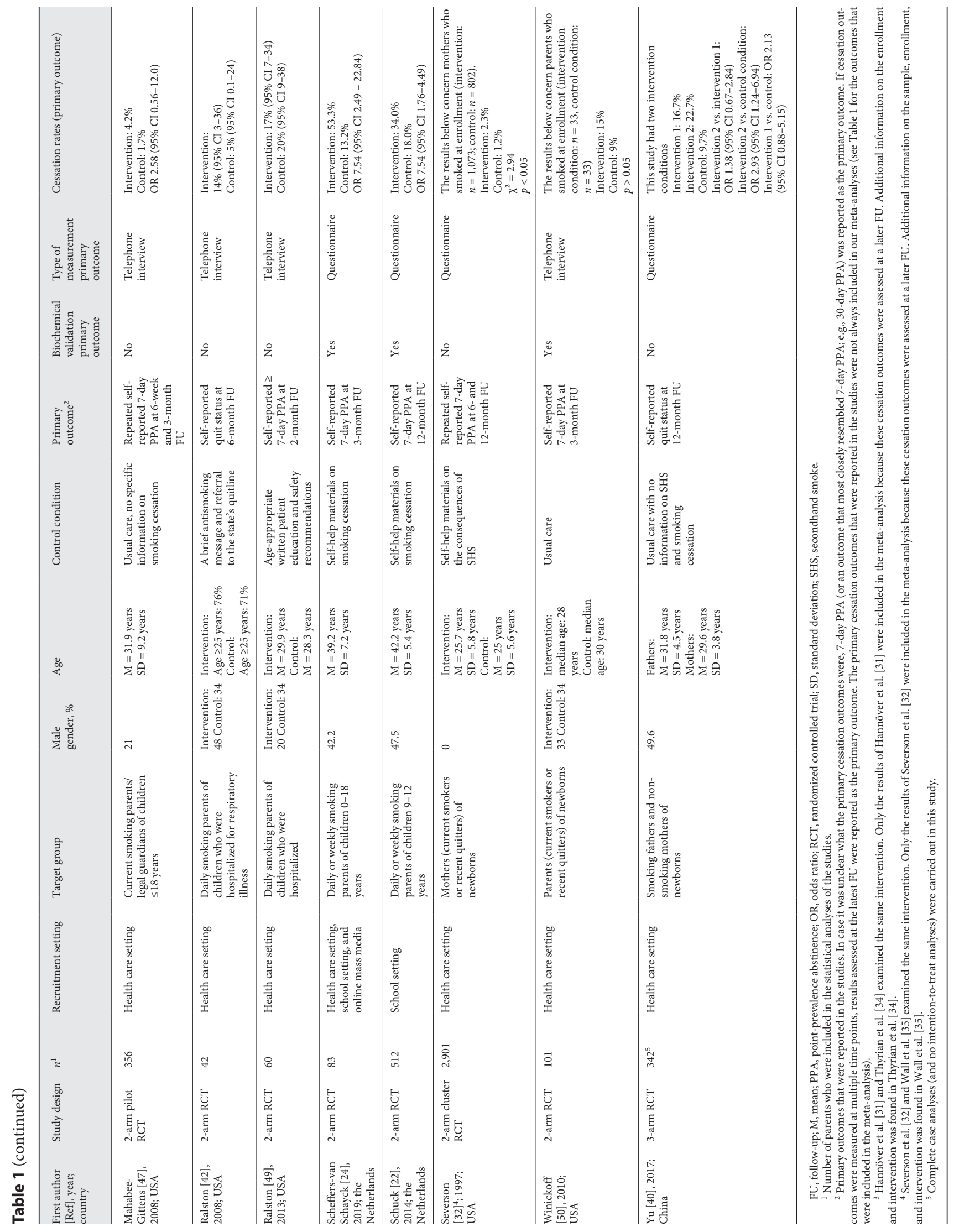




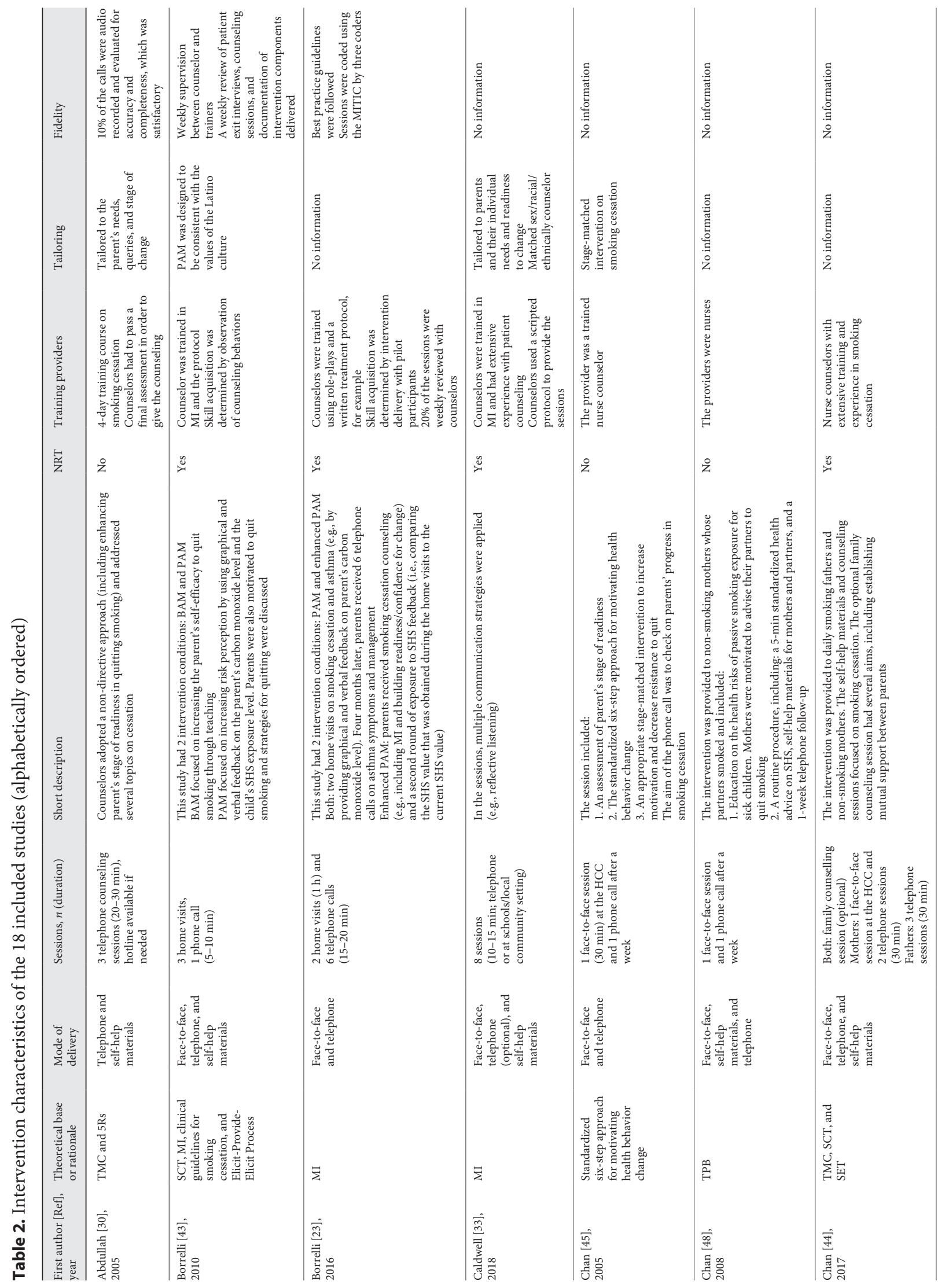




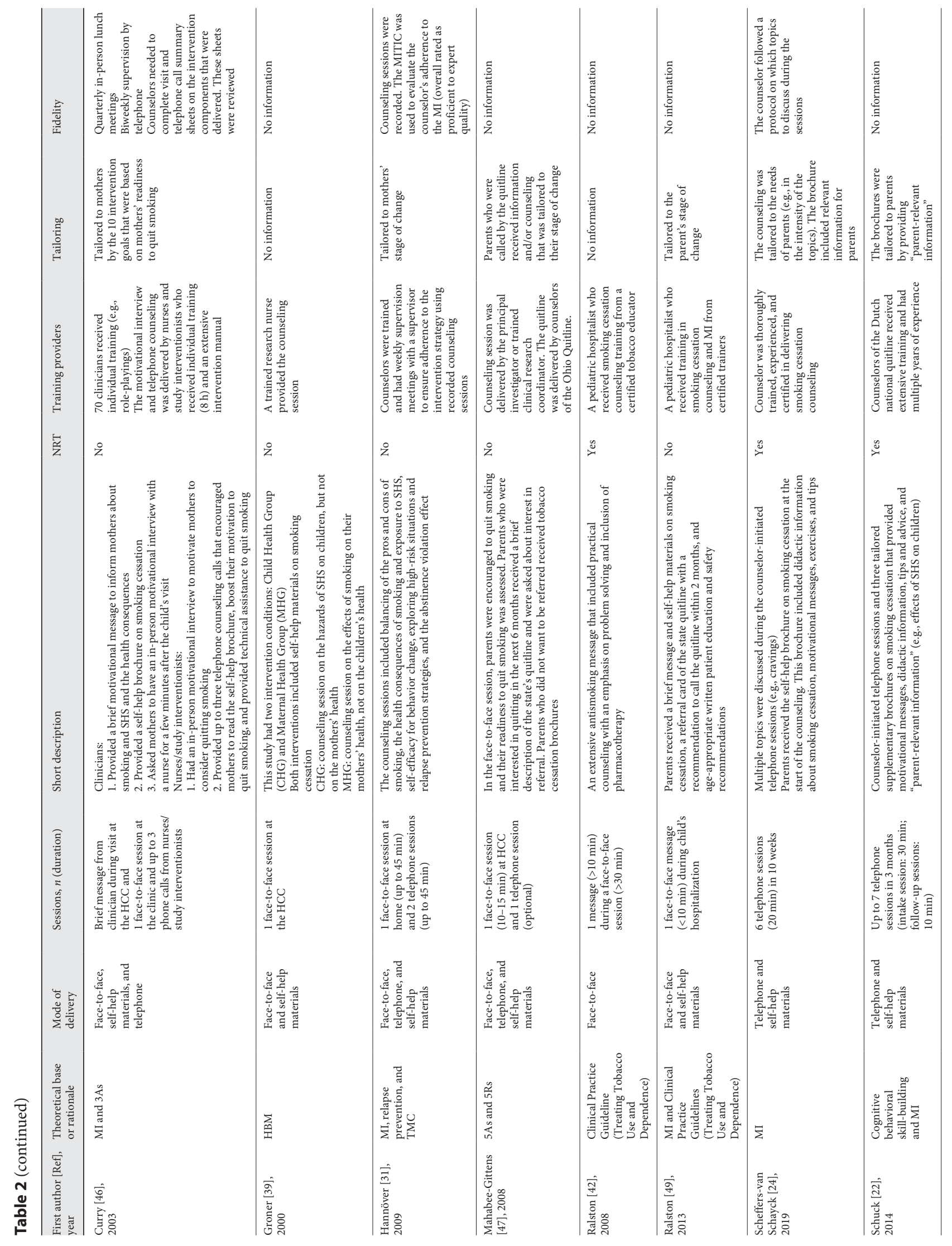




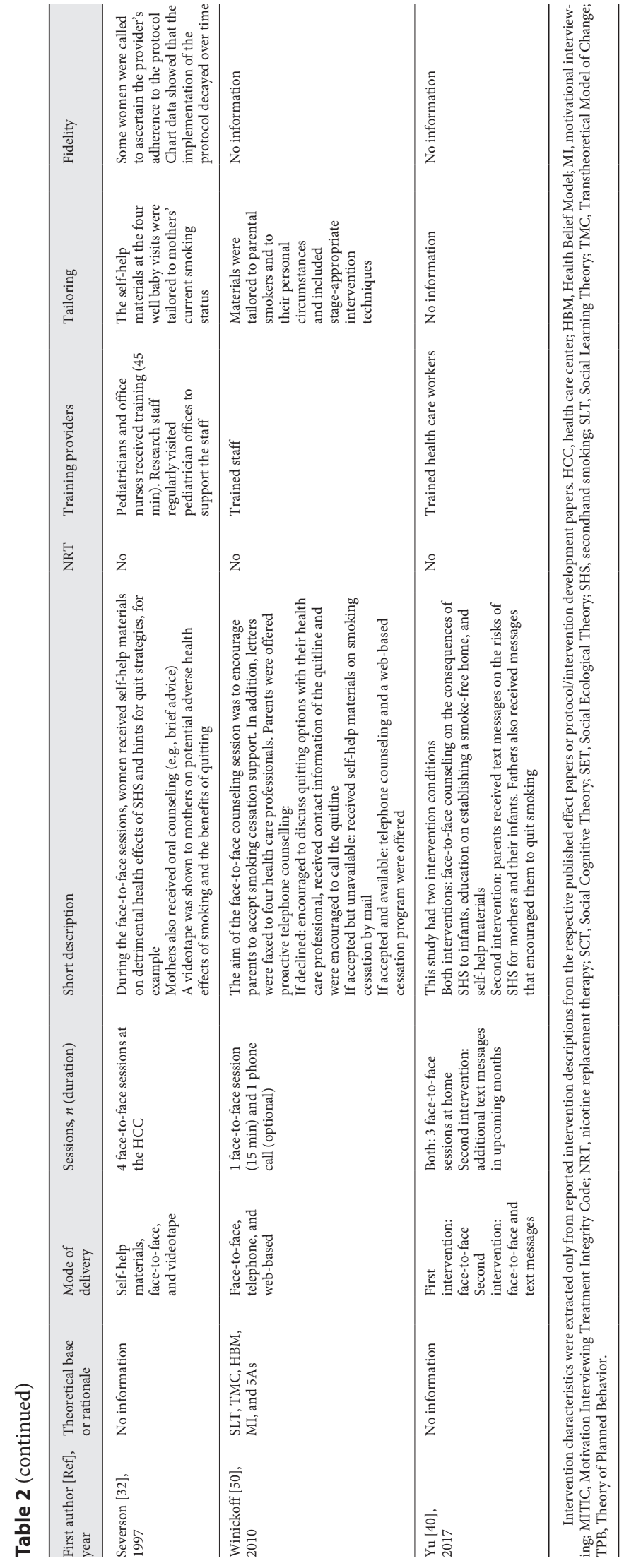

Effectiveness of Parent-Tailored Smoking Cessation Interventions bias assessment were resolved through discussion and, if necessary, by consulting a third author (R.O, or M.K.). Moreover, if important information was not reported in a given article, the authors of that study were contacted for additional information.

\section{Statistical Analyses}

To examine the effectiveness of smoking cessation interventions tailored to parents, meta-analyses were carried out by computing relative risks (RR; using random-effects meta-analyses and the Mantel-Haenszel method) in Review Manager (version 5.3). In addition, four pre-specified subgroup analyses and two sensitivity analyses were performed.

In order to include primary outcomes that were as consistent as possible, we selected 7-day PPA (or an outcome that most closely resembled 7-day PPA; e.g., 30-day PPA) if a study had multiple cessation outcomes. If outcomes were measured at multiple time points, we decided to include the outcome that was assessed at the latest follow-up, which conforms with other related meta-analyses $[15,20]$. The cessation outcomes that were included in our metaanalyses were not always reported as the primary cessation outcomes in the selected studies (see Table 3 for the outcomes that were included in the meta-analysis). Because only a few studies carried out a biochemical validation and we preferred for the outcomes to be as consistent as possible, we chose not to include outcomes that were biochemically validated. If only the results of complete case analyses were reported in the studies, the results concerning the cessation rates were adapted (i.e., missing values at follow-up are recorded as "smoker"). Three of the included studies $[23,39,40]$ were 3 -arm RCTs that included two intervention conditions. Based on the Cochrane Handbook for Systematic Reviews of Interventions [41], we decided to combine the cessation rates of the two intervention conditions in the first two studies, since the rates did not significantly differ $[39,40]$. With respect to the third study [23], the effectiveness of the smoking cessation intervention was only tested between two (and not three) conditions, so no adaptations had to be made. Two other included studies were clusterRCTs [32, 33]. Based on the Cochrane Handbook [41], we decided to apply the intraclass correlation of 0.0009 for quitting, as reported by Severson et al. [32], to the results of the two cluster RCTs to verify for potential biases. To test heterogeneity, the $I^{2}$ statistic, the $95 \%$ confidence intervals (CI) of the effect sizes for each study, and the $\chi^{2}$ test were inspected. If the $\chi^{2}$ test was insignificant $(p>0.05)$, $I^{2}<30 \%$, and the CIs overlapped, there was considered to be no heterogeneity. Funnel plots were created to explore potential publication bias and Egger's test and rank correlation tests were carried out to statistically test the possibility of publication bias. If the funnel plot was asymmetrical and the tests were significant $(p<$ 0.05 ), there was considered to be publication bias.

With respect to the additional statistical analyses, four prespecified subgroup analyses were carried out based on prior research $[15,20]$ : (1) theoretical basis of the intervention (yes/no); (2) provision of NRT during the intervention (yes/no); (3) risk of bias judgement (low risk/some concerns/high risk), and (4) intervention received by parents in the control condition (passive/active). Moreover, to test whether the results of the meta-analysis were robust, sensitivity analyses were performed by replicating the analyses: (1) without the three studies for which the operationalization of the cessation rates was unclear [33, 40, 42], and (2) with the studies that also reported the results of the complete case analyses [22, 33, 40, 43-47]. 
Table 3. Classification of the 18 included studies for the subgroup analyses and risk of bias assessment

\begin{tabular}{|c|c|c|c|c|c|}
\hline $\begin{array}{l}\text { First author [Ref], } \\
\text { year }\end{array}$ & $\begin{array}{l}\text { Outcome included } \\
\text { in meta-analysis }\end{array}$ & $\begin{array}{l}\text { Theoretical } \\
\text { basis of the } \\
\text { intervention }^{1}\end{array}$ & $\begin{array}{l}\text { Provision of } \\
\text { NRT during } \\
\text { intervention }\end{array}$ & $\begin{array}{l}\text { Intervention } \\
\text { delivered to the } \\
\text { control condition }\end{array}$ & Risk of bias \\
\hline $\begin{array}{l}\text { Abdullah [30], } \\
2005\end{array}$ & 7-day PPA at 6-month FU & Yes & No & Active & $\begin{array}{l}\text { Randomization: SC } \\
\text { Blinding: SC } \\
\text { Missing data: LR } \\
\text { Measurement of the outcome: SC } \\
\text { Selection of the results: SC } \\
\text { Overall: SC }\end{array}$ \\
\hline $\begin{array}{l}\text { Borrelli [43], } \\
2010\end{array}$ & 7-day PPA at 3-month FU & Yes & Yes & Active & $\begin{array}{l}\text { Randomization: LR } \\
\text { Blinding: SC } \\
\text { Missing data: SC } \\
\text { Measurement of the outcome: SC } \\
\text { Selection of the results: SC } \\
\text { Overall: SC }\end{array}$ \\
\hline $\begin{array}{l}\text { Borrelli [23], } \\
2016\end{array}$ & 7-day PPA at 12-month FU & Yes & Yes & Active & $\begin{array}{l}\text { Randomization: HR } \\
\text { Blinding: SC } \\
\text { Missing data: SC } \\
\text { Measurement of the outcome: SC } \\
\text { Selection of the results: SC } \\
\text { Overall: HR }\end{array}$ \\
\hline $\begin{array}{l}\text { Caldwell [33], } \\
2018\end{array}$ & Quit status at 48 -month FU & Yes & Yes & Active & $\begin{array}{l}\text { Randomization: SC } \\
\text { Blinding: SC } \\
\text { Missing data: SC } \\
\text { Measurement of the outcome: SC } \\
\text { Selection of the results: SC } \\
\text { Overall: SC }\end{array}$ \\
\hline $\begin{array}{l}\text { Chan [45], } \\
2005\end{array}$ & 7-day PPA at 1 months FU & Yes & No & Passive & $\begin{array}{l}\text { Randomization: SC } \\
\text { Blinding: SC } \\
\text { Missing data: LR } \\
\text { Measurement of the outcome: SC } \\
\text { Selection of the results: SC } \\
\text { Overall: SC }\end{array}$ \\
\hline $\begin{array}{l}\text { Chan [48], } \\
2008\end{array}$ & 7-day PPA at 12-month FU & Yes & No & Active & $\begin{array}{l}\text { Randomization: LR } \\
\text { Blinding: SC } \\
\text { Missing data: SC } \\
\text { Measurement of the outcome: SC } \\
\text { Selection of the results: SC } \\
\text { Overall: SC }\end{array}$ \\
\hline $\begin{array}{l}\text { Chan [44], } \\
2017\end{array}$ & 7-day PPA at 12-month FU & Yes & Yes & Active & $\begin{array}{l}\text { Randomization: SC } \\
\text { Blinding: SC } \\
\text { Missing data: SC } \\
\text { Measurement of the outcome: SC } \\
\text { Selection of the results: SC } \\
\text { Overall: SC }\end{array}$ \\
\hline $\begin{array}{l}\text { Curry [46], } \\
2003\end{array}$ & 7-day PPA at 12-month FU & Yes & No & Not reported ${ }^{2}$ & $\begin{array}{l}\text { Randomization: LR } \\
\text { Blinding: SC } \\
\text { Missing data: SC } \\
\text { Measurement of the outcome: SC } \\
\text { Selection of the results: SC } \\
\text { Overall: SC }\end{array}$ \\
\hline $\begin{array}{l}\text { Groner [39], } \\
2000\end{array}$ & 7-day PPA at 6-month FU & Yes & No & Passive & $\begin{array}{l}\text { Randomization: SC } \\
\text { Blinding: SC } \\
\text { Missing data: SC } \\
\text { Measurement of the outcome: LR } \\
\text { Selection of the results: SC } \\
\text { Overall: SC }\end{array}$ \\
\hline
\end{tabular}


Table 3 (continued)

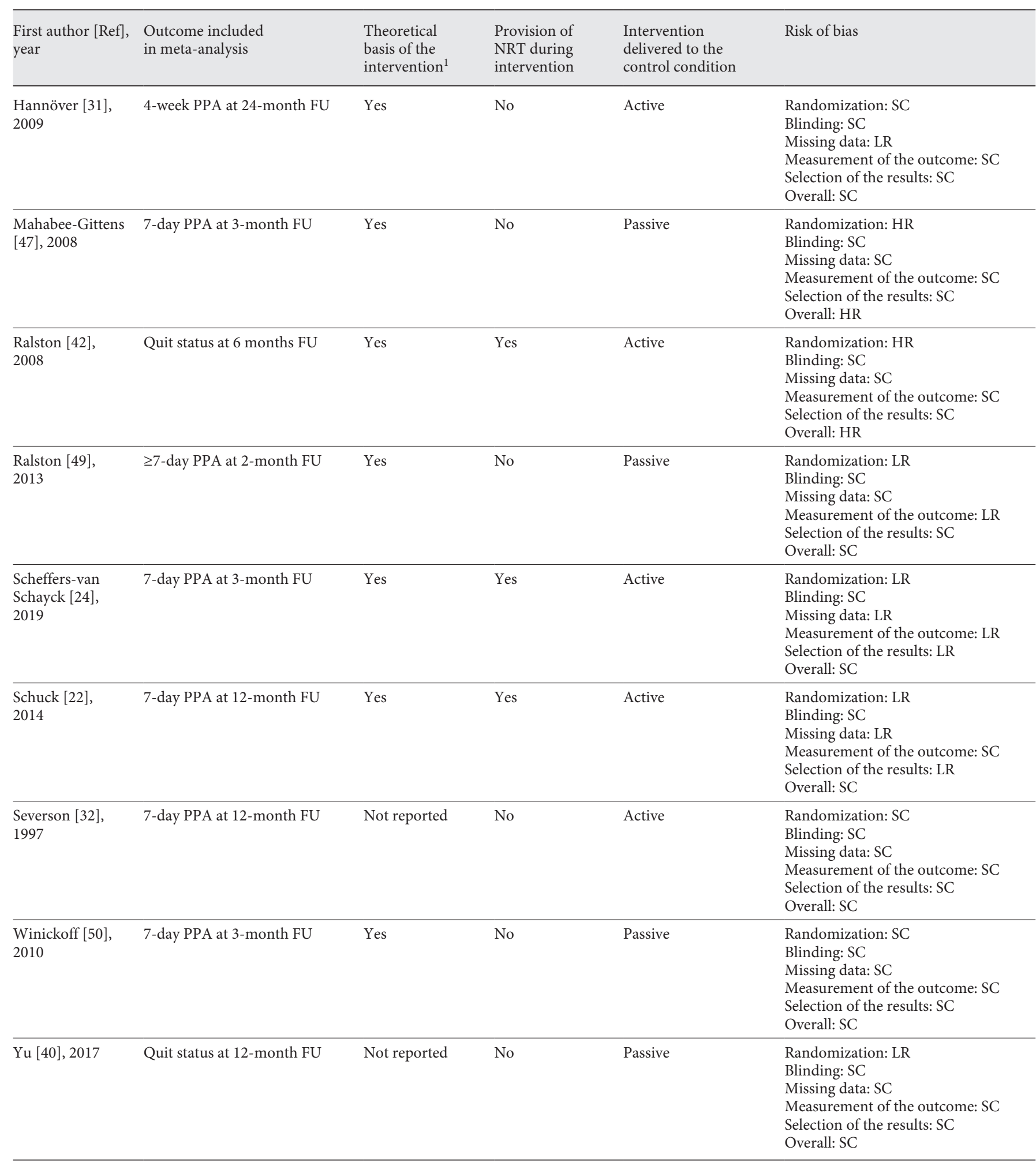

FU, follow-up; HR, high risk; LR, low risk; NRT, nicotine replacement therapy; PPA, point-prevalence abstinence; SC, some concerns.

${ }^{1}$ Because little variance was found between the two subgroups, no subgroup analysis was performed.

${ }^{2}$ No information was provided on what parents in the control condition received in Curry et al. [46]. Therefore, this study was not included in the subgroup analysis. 


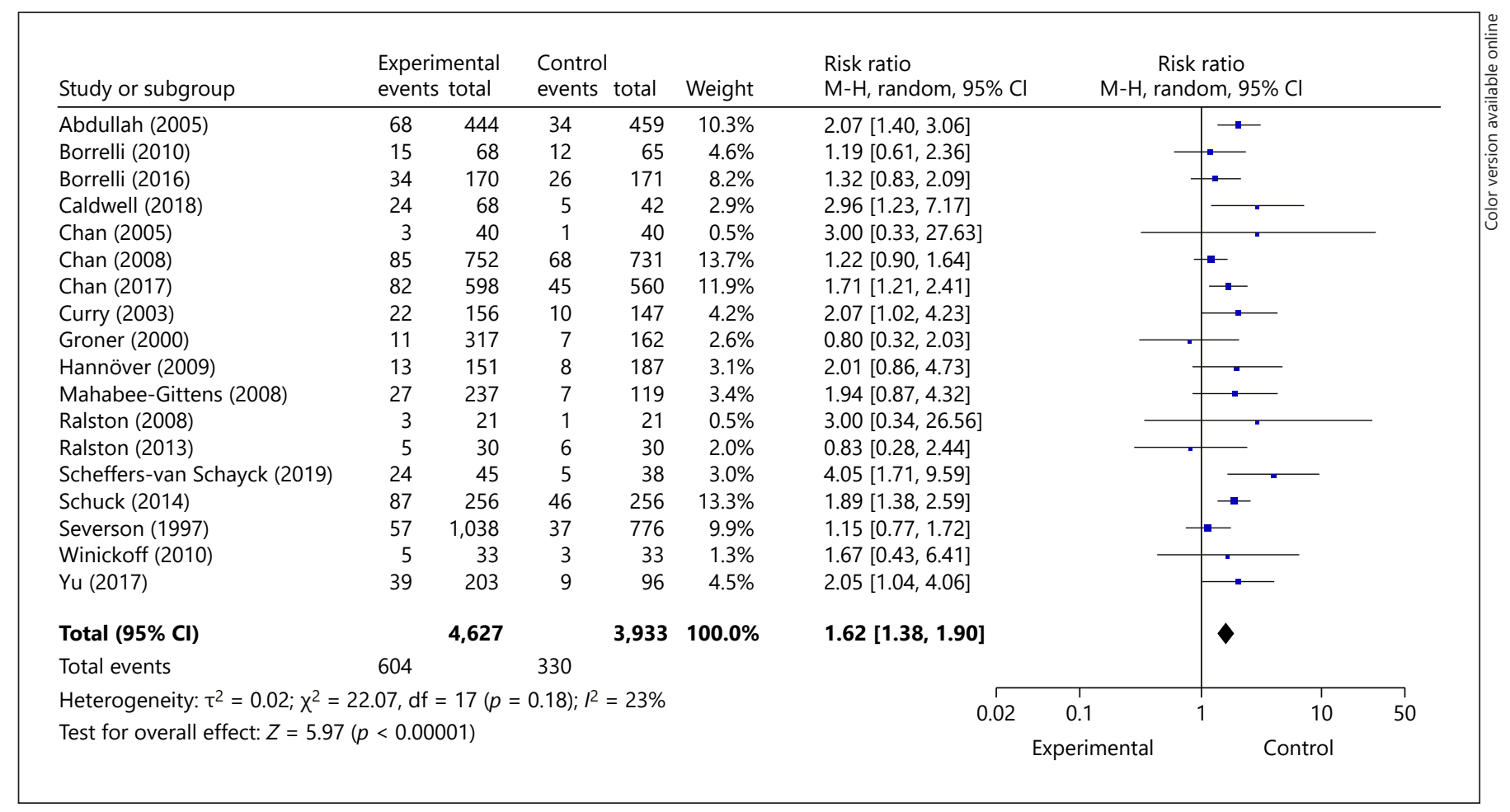

Fig. 2. Meta-analysis of RRs of the effects of smoking cessation interventions tailored to parents.

\section{Results}

\section{Description of Included Studies}

Table 1 provides an overview of the characteristics of the studies included in this meta-analysis. All 18 studies were RCTs, divided into 16 individual RCTs (of which two were pilot-RCTs $[45,47])$ and two cluster-RCTs [32, 33]. Although most studies had two conditions, three studies had three conditions $[23,39,40]$. There were also some small differences in the recruitment settings used. In total, 13 studies recruited parents via a health care setting [30-32, 39, 40, 42, 44-50], two studies recruited parents via schools $[22,33]$, and three studies recruited parents via various settings $[23,24,43]$. In addition, the included studies differed by publication date (one before 2000 [32], eight between 2000 and 2009 [30, 31, 39, 42, $45-48]$, and nine in or after 2010 [22-24, 33, 40, 43, 44, $49,50])$, the country in which the studies were conducted (ten in the USA [23, 32, 33, 39, 42, 43, 46, 47, 49, 50], five in China [30, 40, 44, 45, 48], two in the Netherlands [22, $24]$, and one in Germany [31]), and the sample sizes (from 42 [42] to 2,901 parents [32]). Finally, the majority of studies focused on the smoking behavior of both fathers and mothers [22, 23, 24, 30, 33, 42, 43, 45, 47, 49, 50], while seven studies only focused on maternal $(n=4[31$, $32,39,46])$ or paternal smoking behavior $(n=3[40,44$, 48]).

\section{Description of the Interventions}

Table 2 presents an overview of the characteristics of the interventions that were examined in the included studies. The majority $(n=15)$ of the interventions were delivered face-to-face [23, 31-33, 39, 40, 42-45, 47-51]. All interventions included multiple sessions (face-to-face and/or telephone), except for three interventions that included only one session $[39,42,49]$. In addition, most interventions had a theoretical base or rationale. Only two studies did not report any information on this [32, 40]. In less than half $(n=7)$ of the interventions, parents received some form of NRT (or were encouraged to use NRT) [22-24, 33, 42-44]. Finally, 12 studies reported some information on tailoring of the intervention to parents [22, 24, 30-33, 43, 45, 47, 49-51].

\section{Risk of Bias Assessment}

The risk of bias assessment of the 18 included studies can be found in Table 3. Both the judgement for all criteria and the overall judgement are depicted. As illustrated 


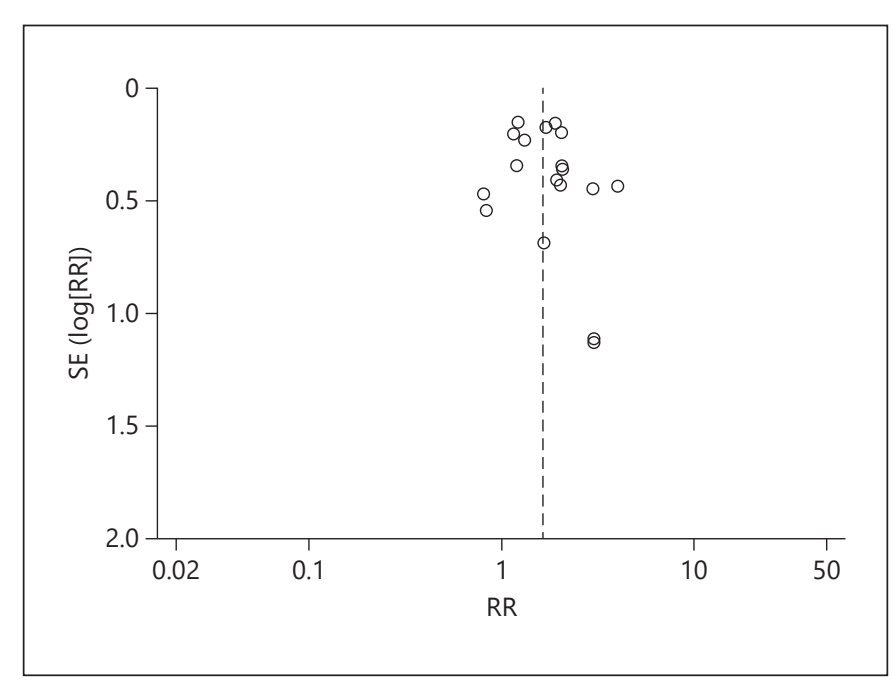

Fig. 3. Funnel plot of pooled effects of smoking cessation interventions tailored to parents.

in Table 3, 15 studies scored "some concerns." All three of the other studies scored "high risk" on the overall judgement because an urn randomization procedure was carried out [23] or because baseline imbalances were found on smoking-related variables between the conditions $[42,47]$.

\section{Intervention Effects and Subgroup Analyses}

The results of the meta-analysis are displayed in Figure 2. With a total number of 8,560 parents, the pooled RR was 1.62 (95\% CI 1.38-1.90; $p<0.00001)$, showing a significant but modest effect. Overall, $13.1 \%$ of parents in the intervention conditions versus $8.4 \%$ of the parents in the control conditions reported smoking abstinence. The funnel plot did not show noteworthy deviations (Fig. 3). In addition, the Egger's test and the rank correlation test did not yield significant results (Egger's test: $p=0.38$; rank correlation test: $p=0.50$ ), indicating no risk of publication bias. Although heterogeneity was low $\left(I^{2}=23 \% ; \chi^{2}=\right.$ 22.07; $p=0.18$ ), pre-specified subgroup analyses were carried out. Results revealed no significant differences for provision of NRT during the intervention (yes: RR 1.79; 95\% CI 1.40-2.29 vs. no: RR 1.49; 95\% CI 1.22-1.83), risk of bias in overall judgement (some concerns: RR 1.64; 95\% CI $1.37-1.98$ vs. high risk: RR 1.48; 95\% CI 1.00 $2.20)$, and intervention delivered to the control condition (passive: RR 1.51; 95\% CI 1.02-2.23 vs. active: RR 1.64; 95\% CI 1.36-1.90). Eventually, no subgroup analysis was performed concerning the theoretical basis of the intervention, because little variance was found between the two subgroups (Table 3). The classification of the studies for the subgroup analyses can be found in Table 3 . To test the robustness of the overall results, sensitivity analyses were performed by replicating the model without the three studies $[33,40,42]$ of which the operationalization of the smoking cessation outcome was unclear. Results revealed a pooled RR of 1.57 (95\% CI 1.33-1.86; $p<$ $0.00001 ; I^{2}=27 \%$ ), indicating no substantial difference. The second sensitivity analysis, in which only studies were included that reported the results of the complete case analyses [22, 33, 40, 43-47], revealed a pooled RR of 1.79 (95\% CI 1.29-2.47; $p<.00001 ; I^{2}=79 \%$ ).

\section{Discussion}

This meta-analysis provides an overview of smoking cessation interventions tailored to parents of children and adolescents (aged $0-18$ years). The overall results revealed that $13.1 \%$ of the parents in the intervention conditions reported smoking abstinence at follow-up compared to $8.4 \%$ of the parents in the control conditions. The pooled risk ratio showed that parents in the intervention conditions were 1.62 times more likely to quit smoking than parents in the control conditions, representing a significant but modest effect. Yet, small effect sizes can still have important implications [52]. Even though some of the included studies yielded higher effect sizes (e.g., Abdullah et al. [30], Hannöver et al. [31], Scheffers-van Schayck et al. [24], and Schuck et al. [22]), the overall results suggest that improvement of smoking cessation interventions tailored to parents is warranted.

Smoking cessation interventions tailored to parents might be improved by combining these interventions with a tobacco prevention intervention for children. If parents receive a smoking cessation intervention and are asked to provide antismoking socialization to their children (e.g., to talk to their children about their experiences with smoking), parents could experience less cognitive dissonance, for example, because their smoking status and their expressions of antismoking values to their children will match [53]. This hypothesis was supported in an RCT in which a relapse prevention intervention for parents who had quit smoking for $\geq 24 \mathrm{~h}$ was tested. Parents in the intervention condition were encouraged to provide antismoking socialization to their children whereas parents in the control condition received no treatment. Results showed that this intervention was effective in both the short and long term (3-year follow-up) $[53,54]$. This finding corresponds to one of the studies 
included in this meta-analysis, which examined an intervention that focused on both parental smoking cessation and prevention of children initiating smoking [33]. Its results showed that the self-reported abstinence rates of parents in the intervention condition significantly increased in the longer term (from 6\% at end of the treatment/2-year follow up to $41 \%$ at the 4 -year followup, $p<0.001$ ). In addition, significantly more parents in the intervention condition reported abstinence compared to the parents in the control condition at the 4-year follow-up (41 vs. $13 \%, \mathrm{p}<0.001$ ). Although the biochemical validation did not find significant differences between the two conditions at the 4-year follow-up, the authors suggested that the high abstinence rates of parents in the intervention condition at the 4-year follow-up could be explained by the fact that children were enrolled in a school- and home-based tobacco prevention intervention. Further research is needed to gain more insight into whether a smoking cessation intervention for parents in which they are also engaged in providing antismoking socialization to their children, or the combination of a smoking cessation intervention for parents and a school-based tobacco prevention intervention for children, could increase the abstinence rates of parents more than when parents only receive a smoking cessation intervention.

Although the overall results showed that the smoking cessation interventions tailored to parents had a modest effect in terms of smoking abstinence, some of the included studies that had lower risk of bias (i.e., no score of "high risk" and $\geq 1$ score of "low risk" on any of the criteria of the risk of bias assessment) revealed higher effect sizes (e.g., Abdullah et al. [30], Hannöver et al. [31], Scheffers-van Schayck et al. [24], Schuck et al. [22], and $\mathrm{Yu}$ et al. (2017) [40]). These results indicate that not all included smoking cessation interventions have to be improved and that some of these interventions could be ready for implementation. It is important to examine how these interventions can be successfully implemented by investigating how parents can be reached and encouraged to accept and use the interventions. A related question concerns how the costs that parents possibly have to pay to receive the interventions could be reimbursed (e.g., by health insurance) so that more parents are able to accept these evidence-based interventions. A couple of the included studies in this meta-analysis reported information about the costs of the interventions. For example, in a study that was based on data from the USA, Severson et al. [35] reported that mothers had to pay up to USD 25 for the intervention. In contrast, Scheffers-van Schayck et al. [26] reported higher costs of the intervention in the Netherlands (range EUR 302.50-363). However, the amount that these parents actually had to pay for the intervention depended on their health insurance. In other studies, parents received NRT or the behavior counseling for free $[22,23,43,44,49]$. A Cochrane review showed that full reimbursement of smoking cessation interventions (vs. no reimbursement) increased the use of interventions, the number of quit attempts, and the abstinence rates at 6 months or longer [55]. In contrast, partial reimbursement versus no reimbursement did not significantly increase the use of smoking cessation interventions [55]. Thus, full reimbursement could increase the impact of smoking cessation interventions in its effectiveness and acceptance by smokers.

The pooled risk ratio of this meta-analysis corresponds to a large extent to the pooled risk ratio of 1.69 (95\% CI $1.2-2.4, p=0.003)$ that was found in a previous subgroup analysis [15]. However, in contrast to previous research $[15,20]$, we did not find any significant differences in the subgroup analyses concerning the provision of NRT during the intervention and the intervention that was delivered to the control condition (passive/active). These results could be explained by the fact that we included more studies and our studies primarily focused on parental smoking cessation (and not on reduction of exposure to SHS). Both sensitivity analyses yielded quite similar effect sizes compared to the effect size of the main analysis. The effect size of the first subgroup analysis (that excluded three studies for which the operationalization of the cessation rates was unclear) was smaller than the effect size of the main analysis (RR 1.57). The somewhat larger effect size (RR 1.79) of the second subgroup analysis (that only included complete cases) could be explained by the fact that this subgroup analysis did not include the cessation rates of parents who did not complete the follow-up assessment, therefore yielding a more positive (biased) image of the effectiveness of the interventions [56]. Yet, the fact that the results of the sensitivity analyses did not substantially differ from the results of the main analysis underlines the robustness of these results.

\section{Limitations}

This meta-analysis had several limitations. First, we were unable to include biochemically validated abstinence rates in our meta-analysis. Although guidelines recommend the use of biochemical validation [56], only $50 \%$ of the included studies validated abstinence rates biochemically. Because we aimed at having outcomes that were as consistent as possible, we decided to include only 
self-reported abstinence rates. A second methodological limitation is that none of the included studies scored "low risk" on the overall judgement of the risk of bias assessment, while three studies scored "high risk," indicating that the results of the included studies (and therefore also the results of this meta-analysis) could have been biased. In particular, there is a possibility of selection bias in three of the included studies due to limitations in the randomization of parents to the interventions $[23,42,47]$. Therefore, caution is needed in interpreting the results of the present meta-analysis. In addition, the fact that all included studies scored at least "some concerns" on the overall judgement indicates that future research should be methodologically improved, and guidelines (e.g., the CONSORT statement [57]) should be followed in the reporting of future studies. Finally, although eight of the studies included only parents who smoked cigarettes $[23,39,40,43$, $44,46,49,50]$, in other studies it was not clear whether parents only smoked cigarettes or whether they also used other tobacco products (e.g., e-cigarettes [58]). Related to this, most studies did not report whether the interventions only aimed at stopping smoking cigarettes or if it also impacted the use of other tobacco products. This is a limitation as the smoke of other tobacco products also contains pollutants [59], which urges the need for knowledge about the effects of smoking cessation interventions on the use of other tobacco products as well.

\section{Conclusion}

To the best of our knowledge, this is the first metaanalysis on interventions that are primarily aimed at helping parents (of children and adolescents aged 0-18 years) to quit smoking. Although the results of this metaanalysis should be interpreted with caution and some of the included interventions yielded promising results, overall results suggest that smoking cessation interventions tailored to parents are modestly effective. Future studies should test which factors of smoking cessation interventions (with high effect sizes) make these interven- tions effective in terms of smoking abstinence. For instance, are interventions more effective when children of smoking parents experience smoking-related health problems? To increase the effectiveness and the impact of these interventions in terms of public health and controlling tobacco use, it is crucial for further research to explore how these interventions can be improved.

\section{Acknowledgements}

The authors would like to thank Angita Peterse for carrying out the systematic literature search.

\section{Statement of Ethics}

All studies that were included in the present meta-analysis provided information with approval by the institute's committee on human research and/or after obtaining active informed consent of the participants.

\section{Conflict of Interest Statement}

The authors have no conflicts of interest to declare.

\section{Funding Sources}

This study was supported by the Dutch Cancer Society (grant No. 2015-7944). The funding body had no role in the design of the study, data collection, analysis, and interpretation of the data, or in writing the manuscript.

\section{Author Contributions}

T.S.-v.S. was responsible for the literature search, the data selection and extraction process, quality assessment, and reporting the study results. A.M. contributed to the data selection and extraction process and quality assessment. A.M., R.O., R.E., and M.K. reviewed and contributed to earlier versions of the manuscript. All authors read and approved the final manuscript.

\section{References}

1 Mbulo L, Palipudi KM, Andes L, Morton J, Bashir R, Fouad H, et al.; GATS Collaborative Group. Secondhand smoke exposure at home among one billion children in 21 countries: findings from the Global Adult Tobacco Survey (GATS). Tob Control. 2016 Dec;25 e2:e95-100.
2 Johansson A, Hermansson G, Ludvigsson J. How should parents protect their children from environmental tobacco-smoke exposure in the home? Pediatrics. 2004 Apr; 113(4):e291-5.
3 Matt GE, Quintana PJ, Destaillats H, Gundel LA, Sleiman M, Singer BC, et al. Thirdhand tobacco smoke: emerging evidence and arguments for a multidisciplinary research agenda. Environ Health Perspect. 2011 Sep;119(9): 1218-26. 
4 US Department of Health and Human Services. The health consequences of involuntary exposure to tobacco smoke: a report of the surgeon general. Atlanta: US Department of Health and Human Services, Centers for Disease Control and Prevention, Coordinating Center for Health Promotion, National Center for Chronic Disease Prevention and Health Promotion, Office on Smoking and Health; 2006.

5 Öberg M, Jaakkola MS, Woodward A, Peruga A, Prüss-Ustün A. Worldwide burden of disease from exposure to second-hand smoke: a retrospective analysis of data from 192 countries. Lancet. 2011 Jan;377(9760):139-46.

6 Hofhuis W, de Jongste JC, Merkus PJ. Adverse health effects of prenatal and postnatal tobacco smoke exposure on children. Arch Dis Child. 2003 Dec;88(12):1086-90.

7 Acuff L, Fristoe K, Hamblen J, Smith M, Chen J. Third-hand smoke: old smoke, new concerns. J Community Health. 2016 Jun;41(3): 680-7.

8 Ferrante G, Simoni M, Cibella F, Ferrara F, Liotta G, Malizia V, et al. Third-hand smoke exposure and health hazards in children. Monaldi Arch Chest Dis. 2013 Mar;79(1):38-43.

9 Clergue-Duval V, Mary-Krause M, Bolze C, Fombonne E, Melchior M. Early predictors of trajectories of tobacco use level from adolescence to young adulthood: a 16-year followup of the TEMPO Cohort Study (1999-2015). Eur Addict Res. 2019;25(1):2-9.

10 Otten R, Engels RC, van de Ven MO, Bricker JB. Parental smoking and adolescent smoking stages: the role of parents' current and former smoking, and family structure. J Behav Med. 2007 Apr;30(2):143-54.

11 Harutyunyan A, Movsisyan N, Petrosyan V, Petrosyan D, Stillman F. Reducing children's exposure to secondhand smoke at home: a randomized trial. Pediatrics. 2013 Dec;132(6): 1071-80.

12 Hovell MF, Zakarian JM, Wahlgren DR, Matt GE. Reducing children's exposure to environmental tobacco smoke: the empirical evidence and directions for future research. Tob Control. 2000;9(90002 Suppl 2):II40-7.

13 Bricker JB, Leroux BG, Peterson AV Jr, Kealey KA, Sarason IG, Andersen MR, et al. Nineyear prospective relationship between parental smoking cessation and children's daily smoking. Addiction. 2003 May;98(5):585-93.

14 Doll R, Peto R, Wheatley K, Gray R, Sutherland I. Mortality in relation to smoking: 40 years' observations on male British doctors. BMJ. 1994;309(6959):9011-11.

15 Rosen LJ, Noach MB, Winickoff JP, Hovell MF. Parental smoking cessation to protect young children: a systematic review and meta-analysis. Pediatrics. 2012 Jan;129(1):14152.

16 Hymowitz N, Schwab J, Haddock C, Pyle S, Moore G, Meshberg S. The pediatric resident training on tobacco project: baseline findings from the Parent/Guardian Tobacco Survey. Prev Med. 2005 Jul;41(1):334-41.
17 Halterman JS, Borrelli B, Conn KM, Tremblay $\mathrm{P}$, Blaakman S. Motivation to quit smoking among parents of urban children with asthma. Patient Educ Couns. 2010 May;79(2):152-5.

18 Kanis J, Byczkowski T, Mahabee-Gittens EM. Motivation to quit smoking in parental smokers in the pediatric emergency department. Pediatr Emerg Care. 2014 Aug;30(8):546-51.

19 Tyc VL, Hovell MF, Winickoff J. Reducing secondhand smoke exposure among children and adolescents: emerging issues for intervening with medically at-risk youth. J Pediatr Psychol. 2008 Mar;33(2):145-55.

20 Rosen LJ, Myers V, Hovell M, Zucker D, Ben Noach M. Meta-analysis of parental protection of children from tobacco smoke exposure. Pediatrics. 2014 Apr;133(4):698-714.

21 Rosen LJ, Myers V, Winickoff JP, Kott J. Effectiveness of interventions to reduce tobacco smoke pollution in homes: a systematic review and meta-analysis. Int J Environ Res Public Health. 2015 Dec;12(12):16043-59.

22 Schuck K, Bricker JB, Otten R, Kleinjan M, Brandon TH, Engels RC. Effectiveness of proactive quitline counselling for smoking parents recruited through primary schools: results of a randomized controlled trial. Addiction. 2014 May;109(5):830-41.

23 Borrelli B, McQuaid EL, Tooley EM, Busch AM, Hammond SK, Becker B, et al. Motivating parents of kids with asthma to quit smoking: the effect of the teachable moment and increasing intervention intensity using a longitudinal randomized trial design. Addiction. 2016 Sep;111(9):1646-55.

24 Scheffers-van Schayck T, Otten R, Engels RC, Kleinjan M. Proactive telephone smoking cessation counseling tailored to parents: results of a randomized controlled effectiveness trial. Int J Environ Res Public Health. 2019 Jul; 16(15):2730.

25 ter Weijde W, Croes E, Verdurmen J, Monshouwer K. Factsheet meeroken. Utrecht: Trimbos; 2015.

26 Abbott J, Mccarthy M. Smoking behaviour in homes and around children in Victoria: key findings from the 1998-2008 population surveys. CBRC Research Paper Series No. 40. Melbourne: Cancer Council Victoria; 2009.

27 Moher D, Liberati A, Tetzlaff J, Altman DG; PRISMA Group. Preferred reporting items for systematic reviews and meta-analyses: the PRISMA statement. PLoS Med. 2009 Jul; 6(7):e1000097.

28 DiClemente CC, Dolan-Mullen P, Windsor RA. The process of pregnancy smoking cessation: implications for interventions. Tob Control. 2000;9(90003 Suppl 3):III16-21.

29 Hoffmann TC, Glasziou PP, Boutron I, Milne $\mathrm{R}$, Perera R, Moher D, et al. Better reporting of interventions: template for intervention description and replication (TIDieR) checklist and guide. BMJ. 2014 Mar;348:g1687.

30 Abdullah AS, Mak YW, Loke AY, Lam TH. Smoking cessation intervention in parents of young children: a randomised controlled trial. Addiction. 2005 Nov;100(11):1731-40.
31 Hannöver W, Thyrian JR, Röske K, Grempler J, Rumpf HJ, John U, et al. Smoking cessation and relapse prevention for postpartum women: results from a randomized controlled trial at $6,12,18$ and 24 months. Addict Behav. 2009 Jan;34(1):1-8.

32 Severson HH, Andrews JA, Lichtenstein E, Wall M, Akers L. Reducing maternal smoking and relapse: long-term evaluation of a pediatric intervention. Prev Med. 1997 Jan-Feb; 26(1):120-30.

33 Caldwell AL, Tingen MS, Nguyen JT, Andrews JO, Heath J, Waller JL, et al. Parental smoking cessation: impacting children's tobacco smoke exposure in the home. Pediatrics. 2018 Jan;141(suppl 1):S96-106

34 Thyrian JR, Hannöver W, Grempler J, Röske $\mathrm{K}$, John U, Hapke U. An intervention to support postpartum women to quit smoking or remain smoke-free. J Midwifery Womens Health. 2006 Jan-Feb;51(1):45-50.

35 Wall MA, Severson HH, Andrews JA, Lichtenstein E, Zoref L. Pediatric office-based smoking intervention: impact on maternal smoking and relapse. Pediatrics. 1995 Oct; 96(4 Pt 1):622-8.

36 Abdullah AS, Hedley AJ, Chan SS, Ho WW, Lam TH; Hong Kong Council on Smoking and Health Smoking Cessation Health Centre (SCHC) Steering Group. Establishment and evaluation of a smoking cessation clinic in Hong Kong: a model for the future service provider. J Public Health. 2004 Sep;26(3): 239-44.

37 Tingen MS, Andrews JO, Heath J, Turnmire AE, Waller JL, Treiber FA. Comparison of enrollment rates of African-American families into a school-based tobacco prevention trial using two recruitment strategies in urban and rural settings. Am J Health Promot. 2013 Mar-Apr;27(4):e91-100.

38 Higgins J, Sterne J, Savović J, Page M, Hróbjartsson A, Boutron I, et al. A revised tool for assessing risk of bias in randomized trials. Cochrane Database Syst Rev. 2016;10(suppl 1): 29-31.

39 Groner JA, Ahijevych K, Grossman LK, Rich $\mathrm{LN}$. The impact of a brief intervention on maternal smoking behavior. Pediatrics. 2000 Jan; 105(1 Pt 3):267-71.

40 Yu S, Duan Z, Redmon PB, Eriksen MP, Koplan JP, Huang C. mHealth intervention is effective in creating smoke-free homes for newborns: a randomized controlled trial study in China. Sci Rep. 2017 Aug;7(1):9276.

41 Higgins J, Green S, editors. Cochrane handbook for systematic reviews of Interventions. Version 5. London: The Cochrane Collaboration; 2011.

42 Ralston S, Roohi M. A randomized, controlled trial of smoking cessation counseling provided during child hospitalization for respiratory illness. Pediatr Pulmonol. 2008 Jun; 43(6):561-6.

Scheffers-van Schayck et al. 
43 Borrelli B, McQuaid EL, Novak SP, Hammond SK, Becker B. Motivating Latino caregivers of children with asthma to quit smoking: a randomized trial. J Consult Clin Psychol. 2010 Feb;78(1):34-43.

44 Chan SS, Cheung YT, Fong DY, Emmons K, Leung AY, Leung DY, et al. Family-based smoking cessation intervention for smoking fathers and nonsmoking mothers with a child: a randomized controlled trial. J Pediatr. 2017 Mar; 182:260-266.e4.

45 Chan SS, Lam TH, Salili F, Leung GM, Wong DC, Botelho RJ, et al. A randomized controlled trial of an individualized motivational intervention on smoking cessation for parents of sick children: a pilot study. Appl Nurs Res. 2005 Aug;18(3):178-81.

46 Curry SJ, Ludman EJ, Graham E, Stout J, Grothaus L, Lozano P. Pediatric-based smoking cessation intervention for low-income women: a randomized trial. Arch Pediatr Adolesc Med. 2003 Mar;157(3):295-302.

47 Mahabee-Gittens EM, Gordon JS, Krugh ME, Henry B, Leonard AC. A smoking cessation intervention plus proactive quitline referral in the pediatric emergency department: a pilot study. Nicotine Tob Res. 2008 Dec;10(12): 1745-51.
48 Chan SS, Leung GM, Wong DC, Lam TH. Helping Chinese fathers quit smoking through educating their nonsmoking spouses: a randomized controlled trial. Am J Health Promot. 2008 Sep-Oct;23(1):31-4.

49 Ralston S, Grohman C, Word D, Williams J. A randomized trial of a brief intervention to promote smoking cessation for parents during child hospitalization. Pediatr Pulmonol. 2013 Jun;48(6):608-13.

50 Winickoff JP, Healey EA, Regan S, Park ER, Cole C, Friebely J, et al. Using the postpartum hospital stay to address mothers' and fathers' smoking: the NEWS study. Pediatrics. 2010 Mar;125(3):518-25.

51 Curry SJ, Hollis J, Bush T, Polen M, Ludman EJ, Grothaus L, et al. A randomized trial of a family-based smoking prevention intervention in managed care. Prev Med. 2003 Dec; 37(6 Pt 1):617-26.

52 Prentice D, Miller D. When small effects are impressive. Psychol Bull. 1992;112(1):160-4.

53 Jackson C, Hayes KA, Dickinson DM. Engaging parents who quit smoking in antismoking socialization of children: a novel approach to relapse prevention. Nicotine Tob Res. 2016 May; 18(5):926-33.
54 Hayes KA, Jackson C, Dickinson DM, Miller AL. Providing antismoking socialization to children after quitting smoking: does it help parents stay quit? Am J Health Promot. 2018 Jun;32(5):1257-63.

55 van den Brand FA, Nagelhout GE, Reda AA, Winkens B, Evers SM, Kotz D, et al. Healthcare financing systems for increasing the use of tobacco dependence treatment. Cochrane Database Syst Rev. 2017 Sep;9:CD004305.

56 West R, Hajek P, Stead L, Stapleton J. Outcome criteria in smoking cessation trials: proposal for a common standard. Addiction. 2005 Mar;100(3):299-303.

57 Schulz KF, Altman DG, Moher D; CONSORT Group. CONSORT 2010 Statement: updated guidelines for reporting parallel group randomised trials. BMC Med. 2010 Mar;8(1):18.

58 Lequy E, Wiernik E, Cyr D, Nadif R, Lemogne $\mathrm{C}$, Gomajee R, et al. Poor perceived health is associated with current use of electronic cigarette among current and former smokers: findings from the CONSTANCES Cohort. Eur Addict Res. 2019;25(6):310-9.

59 Baker F, Ainsworth SR, Dye JT, Crammer C, Thun MJ, Hoffmann D, et al. Health risks associated with cigar smoking. JAMA. 2000 Aug;284(6):735-40. 